\title{
Functions of corneal endothelial cells do not change after uptake of superparamagnetic iron oxide nanoparticles
}

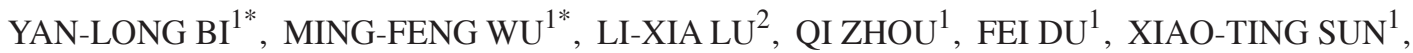 \\ SEN-FEI TANG ${ }^{1}$ and GUO-TONG XU ${ }^{2}$ \\ ${ }^{1}$ Department of Ophthalmology, Tongji Hospital Affiliated to Tongji University School of Medicine, Shanghai 200065; \\ ${ }^{2}$ Department of Regenerative Medicine and Stem Cell Research Center, Tongji University School of Medicine, \\ Shanghai 200092, P.R. China
}

Received January 9, 2013; Accepted March 27, 2013

DOI: $10.3892 / \mathrm{mmr} .2013 .1418$

\begin{abstract}
To avoid donor tissue shortages, ex vivo cultured human corneal endothelial cell (HCEC) transplantation is a promising therapeutic resource. Superparamagnetic iron oxide nanoparticle (SPION) cell labeling assists HCEC transplantation by attaching the posterior corneal stroma in ex vivo animal models. However, possible functional changes of the HCECs following SPION labeling remain to be determined. In this study, we used SPIONs to label cultured rabbit CECs (RCECs) in order to observe important cell functions and the levels of cell markers. The synthetic SPIONs exhibited superparamagnetism at room temperature, with saturation magnetization of $55.4 \mathrm{emu} / \mathrm{g}$ and negligible remanence or coercivity. The $\zeta$-potential was $-24.5 \mathrm{mV}$ and the diameter was $101 \pm 55 \mathrm{~nm}$. Immunostaining demonstrated a normal density of zonula occluden-1 (ZO-1), nestin and $\mathrm{Ki}-67$ at cellular junctions or in nuclei from RCECs following SPION labeling at $16 \mu \mathrm{g} / \mathrm{ml}$. MTT cytotoxicity assay, homotypic adhesion assay, quantitative flow cytometric Ki-67 analysis and RCEC pump function measurement demonstrated no significant differences between the cells with or without SPION labeling $(\mathrm{P}<0.05$, for all assays). Results of this study demonstrated successful labeled cultured RCECs with synthetic SPIONs. Labeled cells possessed several important characteristics required to maintain the transparency and refractive parameters of the cornea, including hexagonal cell morphology, higher cell adhesion ability and proliferative potential, cell pump function and the positive expression of several cell markers.
\end{abstract}

Correspondence to: Professor Guo-Tong Xu, Department of Regenerative Medicine and Stem Cell Research Center, Tongji University School of Medicine, 1239 Siping Road, Shanghai 200092, P.R. China

E-mail: gtxu@tongji.edu.cn

*Contributed equally

Key words: corneal endothelial cell, superparamagnetic iron oxide nanoparticles, cell cycle progression, $\mathrm{Na}^{+} / \mathrm{K}^{+}$-ATPase, short circuit current

\section{Introduction}

Human corneal endothelial cells (HCECs) are composed of a monolayer of hexagonal endothelial cells, which have limited regenerative capacity after birth. A normal density of HCECs and several functions are essential for maintaining corneal transparency $(1,2)$. Corneal edema and blindness occur when a large number of endothelial cells are destroyed by disease or trauma (3-5). This type of blindness, also known as secondary corneal endothelial decompensation, can be cured by corneal transplantation with healthy donor corneas $(6,7)$. However, the majority of individuals cannot be treated by corneal transplantation due to a shortage of cornea donors (8). Transplanting cultured HCECs has long been considered a promising method of expanding the donor pool for endothelial decompensation cases (9). Direct cell seeding into Descemet's membrane has been attempted in human and rabbit models assisted by superparamagnetic iron oxide nanoparticles (SPIONs) $(10,11)$. Under an external magnetic field, the labeled CECs homogeneously adhered to the posterior surface of the corneal stromal bed $(10,11)$. However, following SPION labeling, the dehydrating function required to maintain optical transparency by preventing the stromal layer from becoming excessively hydrated, has not been determined. In this study, we examined electro-osmosis across the endothelial layer and ion channels located in the basolateral and apical membranes. The expression patterns of marker proteins and the adhesive and proliferative ability of the ex vivo cultured SPION-labeled versus unlabeled cells were also determined.

\section{Materials and methods}

Cell culture. Rabbit corneal endothelial cells (RCECs) were isolated from freshly peeled corneal Descemet's membrane of young (8 weeks) New Zealand white rabbit eyes. Peeled endothelia were incubated in a disaggregating solution (300 units type I collagenase, 100 units hyalronidase and $1 \%$ antibiotic/antimycotic solution) in DMEM (Invitrogen, Carlsbad, CA, USA) for $\sim 2 \mathrm{~h}$ at $37^{\circ} \mathrm{C}$. RCECs were collected by centrifugation at $450 \mathrm{x}$ g for $5 \mathrm{~min}$. The cells from two corneas were suspended in a $35-\mathrm{mm}$ petri dish with $2 \mathrm{ml} \mathrm{DMEM} / \mathrm{F} 12$ supplemented with $10 \%$ fetal 
bovine serum (Wisent, Montreal, QC, Canada) and $1 \%$ penicillin and streptomycin (Sigma-Aldrich, St. Louis, MO, USA). Cells were incubated at $37^{\circ} \mathrm{C}$ with $5 \% \mathrm{CO}_{2}$ and passaged 3 days later when they reached $90 \%$ confluency.

All animal protocols were approved by the Tongji University Experimental Animal Center, in accordance with the ARVO Statement for the Use of Animals in Ophthalmic and Vision Research.

Synthesis of dextran-coated SPIONs. Ferric chloride, ferrous sulfate and dextran were purchased from Sigma-Aldrich. To prepare an iron salts solution, two equivalents of ferric chloride and one equivalent of ferrous sulfate were mixed in an aqueous solution. Upon saturation with nitrogen gas, equal volumes of $10 \%$ dextran and $20 \%$ mixed iron salt solution were combined by stirring. Precipitation was achieved by adjusting the $\mathrm{pH}$ to 10.0 with $25 \%$ ammonia solution. The reaction proceeded for $3 \mathrm{~h}$ at $60^{\circ} \mathrm{C}$, with continuous stirring. The SPIONs produced were purified using magnetic separation and ultrafiltration. The hysteresis curves of particles were determined using a vibrating magnetometer (Molspin, Newcastle, UK). Transmission electron microscopy (TEM, JEM-2010, JEOL Ltd., Tokyo, Japan) micrographs were obtained at an accelerating voltage of $200 \mathrm{kV}$. The prepared liposomes were diluted with deionized water and the mean hydrodynamic particle size and $\zeta$-potential were determined at $25^{\circ} \mathrm{C}$ using a Nano S Zetasizer (Malvern Instruments, Malvern, UK). Each experiment was repeated three times.

Labeling of RCECs with SPIONs. Dextran-coated SPIONs, $\sim 50 \mathrm{~nm}$ in size, at a concentration of $5 \mathrm{mg} / \mathrm{ml}$, were added to a $50 \mathrm{ml}$ conical tube containing serum-free RPMI-1640, with 25 mM HEPES, MEM non-essential amino acids, sodium pyruvate and L-glutamine (Biosource, Camarillo, CA, USA). Protamine sulfate (Pro, Sigma-Aldrich), supplied at $10 \mathrm{mg} / \mathrm{ml}$, was prepared as a fresh stock solution of $1 \mathrm{mg} / \mathrm{ml}$ in sterile deionized water immediately prior to labeling. The culture medium was aspirated from the flasks containing RCECs and replaced with media containing SPIONs. Following $2 \mathrm{~h}$ of incubation at $37^{\circ} \mathrm{C}$, an equal amount of complete medium was added to achieve a final SPION concentration of 4-46 $\mu \mathrm{g} / \mathrm{ml}$, respectively. Cells were incubated overnight (16 h) and washed three times with sterile PBS containing $10 \mathrm{U} / \mathrm{ml}$ heparin sulfate (American Pharmaceuticals, Schaumburg, IL, USA).

MTTassay. The cytotoxicity of SPIONs on RCECs was measured by 3-(4,5-dimethyl-2-thiazolyl)-2,5-diphenyl2H-tetrazolium bromide (MTT) (Sigma-Aldrich) assay. Subconfluent cells in a 96-well plate were incubated with SPIONs for 3 and $6 \mathrm{~h}$. MTT $(10 \mu 1,5 \mathrm{mg} / \mathrm{ml})$ in PBS was added to each well and incubated for $5 \mathrm{~h}$. Following the addition of a solution consisting of $10 \%$ sodium dodecyl sulfate (SDS) (Sigma-Aldrich), $5 \%$ isopropyl alcohol and $0.012 \mathrm{~mol} / 1 \mathrm{HCl}$, the 96 -well plate was incubated at $37^{\circ} \mathrm{C}$ overnight. Absorbance values of the 96-well plate were measured at $570 \mathrm{~nm}$ with a reference wavelength of $650 \mathrm{~nm}$ using a SpectraMax reader (Molecular Devices, Sunnyvale, CA, USA).

TEM. RCECs were grown in a $10 \mathrm{~cm}$ petri dish (Nunc, Thermo Fisher Scientific Inc., Waltham, MA, USA) until they achieved
$75 \%$ confluency, then were exposed to SPIONs at the concentrations and times indicated. At the end of the incubation period the cells were washed twice with PBS, detached from the petri dishes with trypsin/EDTA, centrifuged and fixed in $2.3 \%$ cacodylatebuffered glutaraldehyde (Sigma-Aldrich) for $24 \mathrm{~h}$. Samples were postfixed in $1.3 \%$ osmium tetroxide in a $0.2 \mathrm{M}$ cacodylate buffer ( $\mathrm{pH}$ 7.4) for $1 \mathrm{~h}$, dehydrated in graded ethanol solutions, then in propylene oxide, and embedded in 50\% (w/w) epoxy embedding medium, $26 \%$ (w/w) dodecenyl succinic anhydride (DDSA), $23 \%(w / w)$ methyl nadic anhydride and 1\% (w/w) 2,4,6-tris(dimethylaminomethyl)phenol (Sigma-Aldrich). Blocks were cured for $48 \mathrm{~h}$ at $60^{\circ} \mathrm{C}$. Thin sections were cut using an ultramicrotome (Ultracut E, Reichert-Jung Optische Werke AG, Wien, Austria) and mounted on 3 mm 200-mesh copper grids. Grids were stained for $75 \mathrm{~min}$ in saturated uranyl acetate solution (Fluka, St. Louis, MO, USA), then for $100 \mathrm{sec}$ in lead citrate (Ultrostain 2, Laurylab, St. Fons, France). Grids were examined and photographed using a combined Philips CM10 transmission electron microscope and a MegaView III Soft Imaging software system documented the results.

Homotypic adhesion assay. The homotypic adhesion assay was performed as previously reported (8). Monolayer RCECs incubated as described previously, on 24-well plates, were washed gently with PBS three times. Cells $\left(1 \times 10^{5}\right.$ cells), in $1 \mathrm{ml}$ of medium with or without SPION labeling at $16 \mu \mathrm{g} / \mathrm{ml}$, were seeded into each well. The 24 -well plate was placed in a horizontal shaker and agitated at $0.55 \mathrm{x} \mathrm{g}$ at $37^{\circ} \mathrm{C}$. Unattached cells were removed prior to calculating the cell number under a microscope, following incubation for 10, 30 and $60 \mathrm{~min}$. The attached cell numbers were calculated using the formula: number of adherent cells $=1 \times 10^{5}$ - the number of unattached cells.

Immunocytochemistry. For immunocytochemical staining, cells were fixed with $4 \%$ paraformaldehyde (PFA) followed by ice-cold methanol. After blocking with 5\% normal goat serum, the samples were incubated with primary antibodies, including mouse anti-Nestin, rabbit anti-zonula occluden-1 (ZO-1) and anti-Ki67, overnight at $4^{\circ} \mathrm{C}$. Following washing with PBS, the cells were incubated with fluorescein-conjugated secondary antibodies and counterstained with DAPI. Cell staining was examined under a fluorescence microscope (AxioCamMR3, Carl Zeiss, Jena, Germany). Rabbit corneal fibroblasts and epithelial cells were used for negative control staining to exclude contamination from these cells.

Flow cytometric analyses. For Ki67 studies, RCECs prepared with or without SPION labeling were passaged in 1:4 dilutions and dissociated into single cells by $0.25 \%$ trypsin digestion. Cells were fixed in $70 \%$ (w/v) ethanol, washed with PBS and incubated for 20 min with $1 \%$ BSA. RCECs were incubated with a 1:20 dilution of anti-mouse Ki67, washed and incubated with 1:1000 diluted Alexa Fluor 488 conjugated goat anti-mouse IgG (Invitrogen), according to the manufacturer's instructions. Flow cytometric analyses were performed using a FACSCalibur instrument (BD Biosciences, San Jose, CA, USA).

Measurement of corneal endothelial cell pump function. The pump function of confluent monolayers of RCECs was measured 

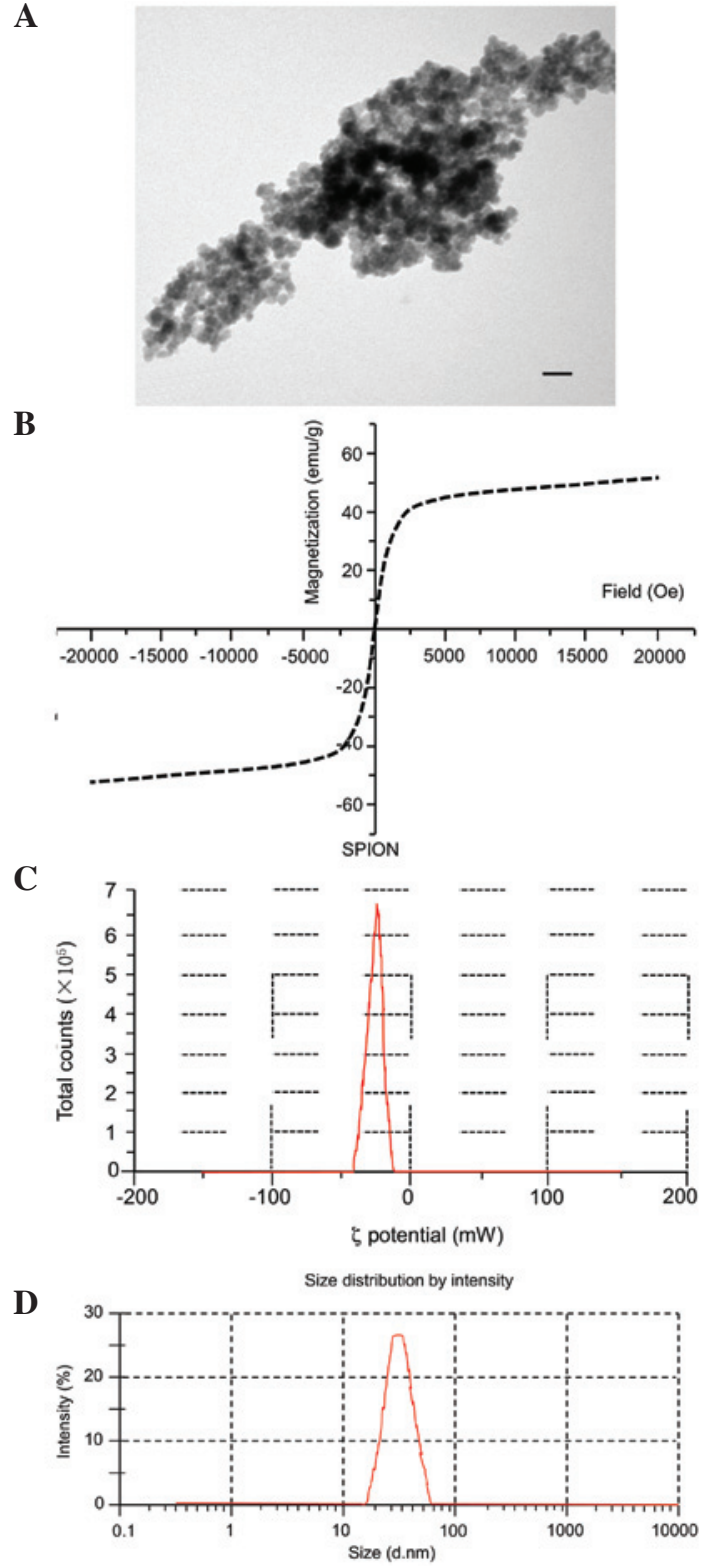

Figure 1. (A) Transmission electron microscopy (TEM) image of SPIONs. Bar, $100 \mathrm{~nm}$. (B) Magnetic hysteresis loop measured at room temperature for the SPIONs. (C) The $\xi$-potential and (D) the size distribution of SPIONs in deionized water. SPIONs, superparamagnetic iron oxide nanoparticles.

using an Ussing chamber as described previously (12). Cells cultured on Snapwell inserts coated with Type IV collagen were placed into the Ussing chamber with the endothelial cell surface side in contact with one chamber and the Snapwell membrane side in contact with another chamber. The chambers were carefully filled with Krebs-Ringer bicarbonate and maintained at $37^{\circ} \mathrm{C}$ using an attached heater. The short circuit current was measured with narrow polyethylene tubes positioned close to either side of the Snapwell insert and filled with $3 \mathrm{M} \mathrm{KCl}$ and $4 \%$ agar gel connected to silver electrodes. These electrodes were connected to the computer through the Ussing system VCC-MC2 (Physiologic Instruments, San Diego, CA, USA) and an iWorx 118 Research Grade Recorder (iWorx Systems, Dover, NH, USA). When the short circuit current had achieved a steady state for $10 \mathrm{~min}$, ouabain $(1 \mathrm{mM})$ was added to the chamber and the short circuit current was measured again.
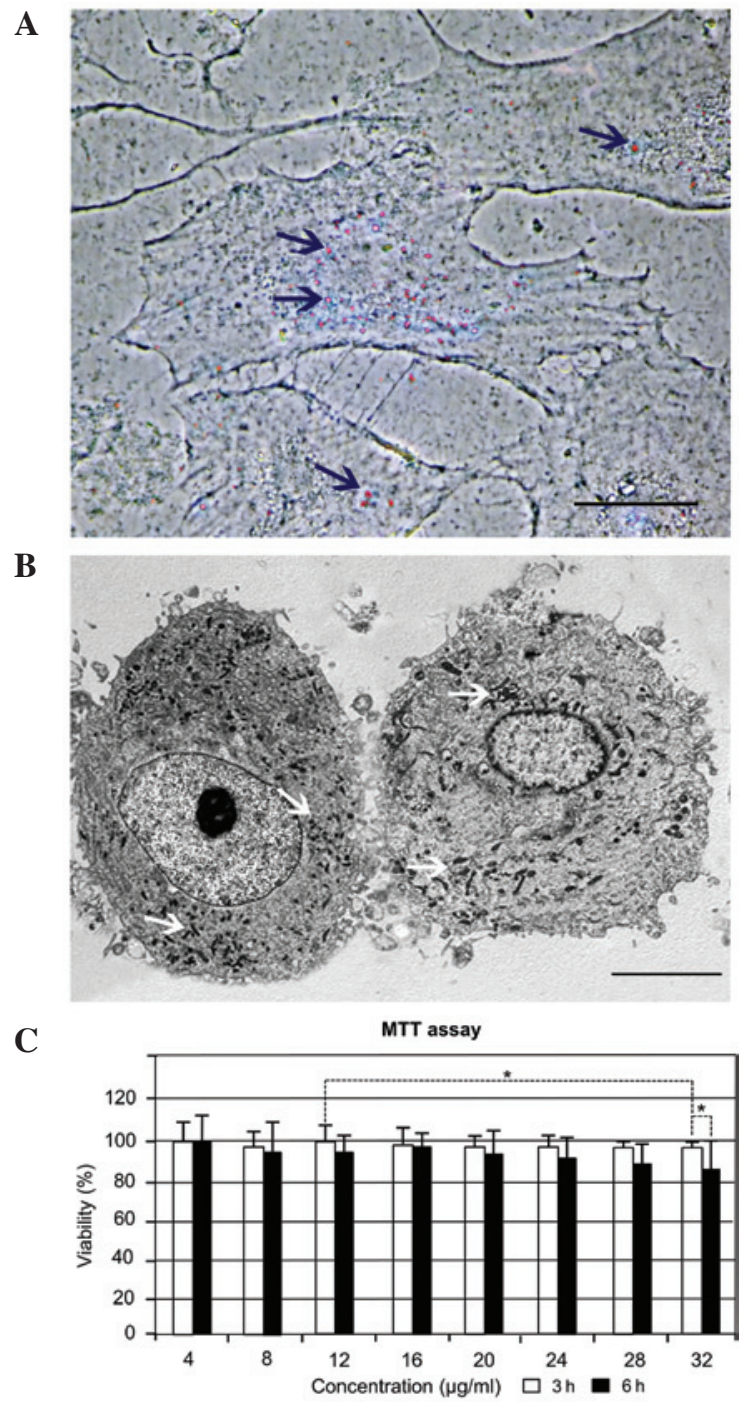

Figure 2. (A) After incubation of SPIONs at a concentration of $16 \mu \mathrm{g} / \mathrm{ml}$ for $3 \mathrm{~h}$, dispersed nanoparticles were found inside the cytoplasm as assessed by Prussian blue staining. (B) TEM images of localization of SPIONs in RCECs after $6 \mathrm{~h}$ exposure. Arrows indicate SPIONs. (C) The effects of SPIONs on cell proliferation and viability of RCECs as determined by MTT assay. Results are represented as the means \pm SD of the mean. ${ }^{*} \mathrm{P}<0.05$. Bar, $5 \mu \mathrm{m}$. SPIONs, superparamagnetic iron oxide nanoparticles; TEM, transmission electron microscopy; RCECs, rabbit corneal endothelial cells.

Statistical analysis. Experimental results were analyzed by one-way analysis of variance using SPSS version 12.0 software (SPSS, IBM, Armonk, NY, USA). Summary statistics are expressed as the means \pm SD. In all statistical analyses, $\mathrm{P}<0.01$ was considered to indicate a statistically significant difference and all $\mathrm{P}$ values were two-sided.

\section{Results}

Characterization of SPIONs. Morphology, size distribution and $\zeta$-potential of the SPIONs are shown in Fig. 1. SPIONs appeared as spherical, well-dispersed particles (Fig. 1A). Hysteresis curves are shown in Fig. 1B. The SPIONs exhibited superparamagnetism at room temperature with saturation magnetization of $55.4 \mathrm{emu} / \mathrm{g}$ and negligible remanence or coercivity. The superparamagnetic character of these particles is demonstrated by the absence of hysteresis. Measurements 

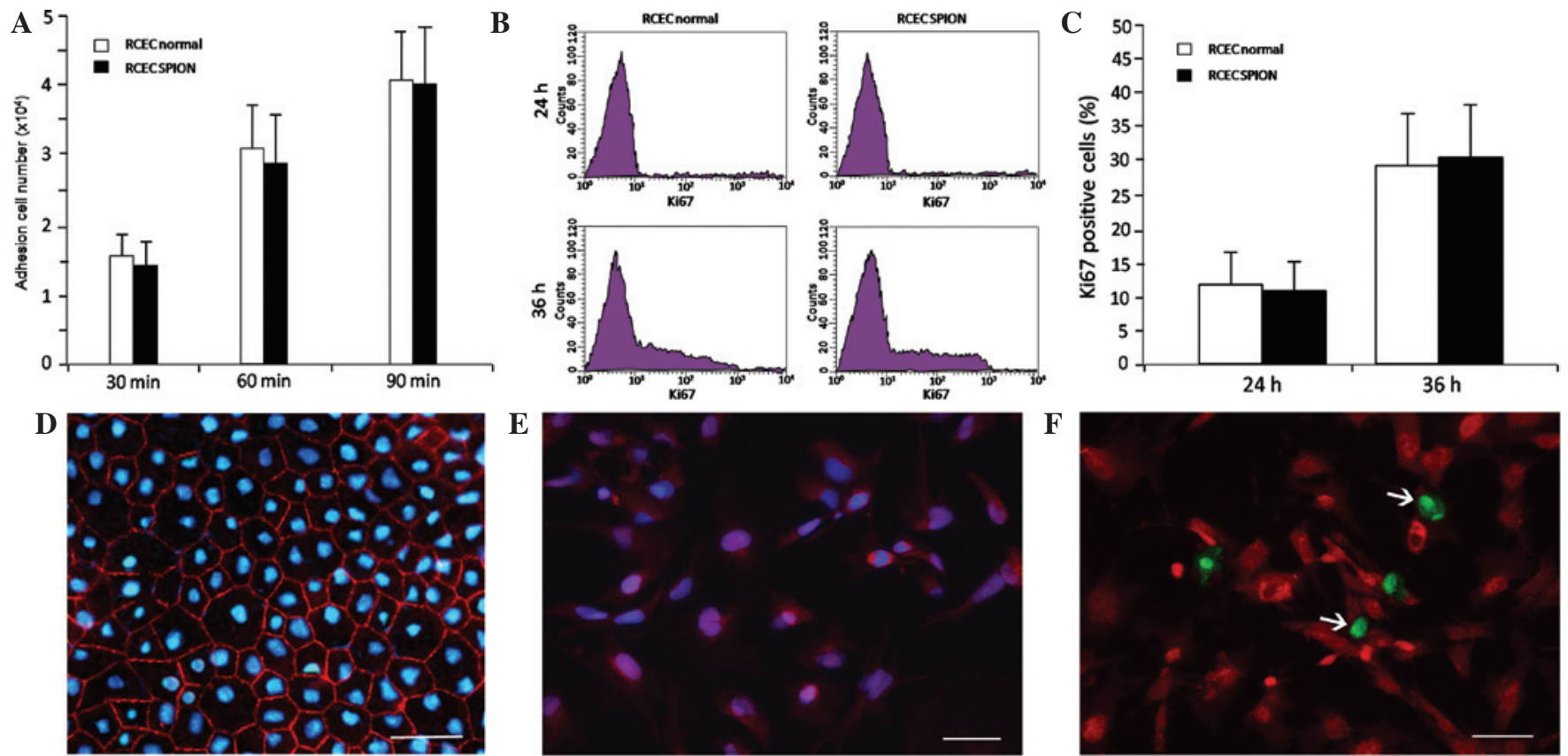

Figure 3. (A) Effects of SPIONs on adhesion of RCECs. RCECs were treated with $16 \mu \mathrm{g} / \mathrm{ml}$ SPIONs for $3 \mathrm{~h}$. (B) Ki67-positive cells were analyzed by flow cytometry. RCECs were subcultured for $36 \mathrm{~h}$ and stained with Ki67 antibody. (C) The number of Ki67-positive cells was not significantly different between the two cell lines at 24 or $36 \mathrm{~h}(\mathrm{P}>0.05)$. Data are expressed as the means $\pm \mathrm{SD}(\mathrm{n}=6)$. Immunostaining revealed that SPION-labeled RCECs stained positively with (D) ZO-1 (E) NES and (F) Ki-67, indicating that they retained some of the original corneal endothelial cell characteristics. Bar, $100 \mu \mathrm{m}$. SPIONs, superparamagnetic iron oxide nanoparticles; RCECs, rabbit corneal endothelial cells; ZO-1, zonula occluden-1; NES, nestin.

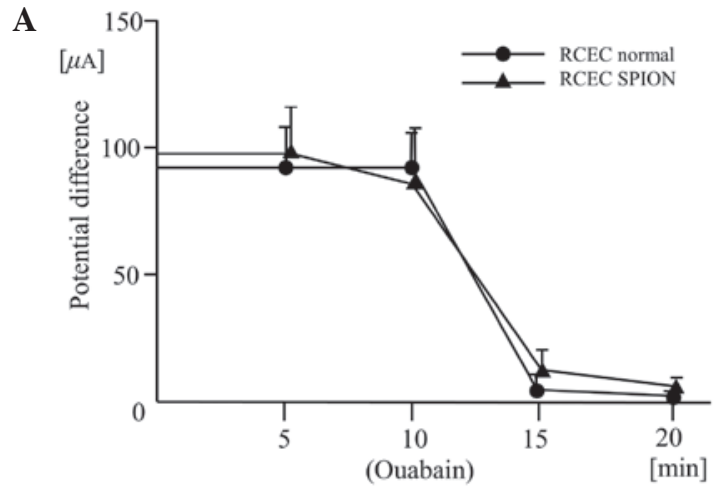

B

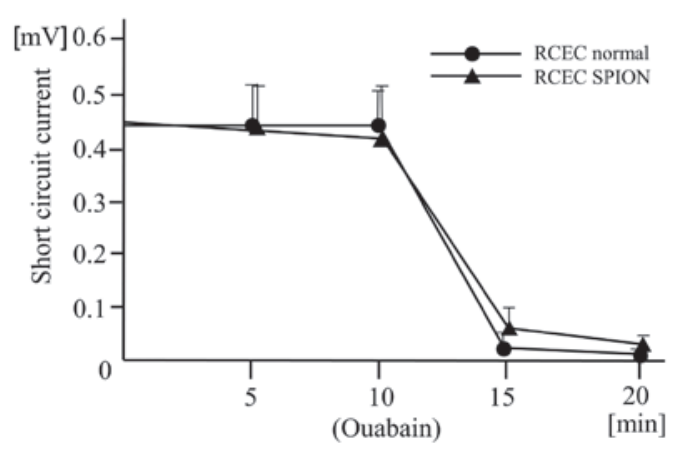

Figure $4 . \mathrm{Na}^{+} / \mathrm{K}^{+}$-ATPase activity representing the pump function of cell lines from corneal cell monolayers on the insert well area of $4.67 \mathrm{~cm}^{2}$. (A) Potential difference (B) and short circuit current were measured prior to and following the addition of the $\mathrm{Na}^{+} / \mathrm{K}^{+}$-ATPase inhibitor ouabain.

were conducted by using ultrasonic vibrations to disperse the SPIONs in double-distilled water. The SPION size distribution was almost homogeneous, with $\zeta$-potentials of $-24.5 \mathrm{mV}$ (Fig. 1C) and diameters of $50.2 \pm 18.1 \mathrm{~nm}$ [polydispersity index (PDI) $=0.202$ ] (Fig. 1D).

SPION cell labeling and cytotoxicity results. Second passage RCECs were treated with SPIONs at concentrations ranging from 4 to $32 \mu \mathrm{g} / \mathrm{ml}$. Nanoparticles were shown to be located within the cytoplasm, following 3-6 h incubation, using Prussian blue staining (Fig. 2A). TEM was used to locate the SPIONs in the cells (Fig. 2B). Following internalization, the SPIONs were located in vesicular structures within the cell cytoplasm (Fig. 2B) and maintained their initial size inside the intracellular vesicles. SPIONs were seldom present in cell vesicles 5 days after the cell culture medium had been replaced. The results of the MTT assay are shown in Fig. 2C and demonstrate that cells exposed to SPIONs at a mean size of $50 \mathrm{~nm}$ for 3 and $6 \mathrm{~h}$ resulted in time- and concentration-dependent cytotoxicity at concentrations $>28 \mu \mathrm{g} / \mathrm{ml}$. At $16 \mu \mathrm{g} / \mathrm{ml}$, SPIONs had no significant cytotoxicity to the RCECs and the viability of cells at 3 and $6 \mathrm{~h}$ was 98.1 and $97.5 \%$, respectively ( $\mathrm{P}>0.05)$. With increasing SPION concentration up to $32 \mu \mathrm{g} /$ $\mathrm{ml}$, the percentage of viable cells decreased to $\sim 96.2 \%$ in $3 \mathrm{~h}$. When the cells were incubated with the same concentration of SPIONs for $6 \mathrm{~h}$, cell viability decreased to $87.5 \%$.

Effects of SPIONs on adhesion, proliferation and markers of RCECs. To investigate the effect of the SPIONs on the adhesion of RCECs, a homotypic adhesion assay was performed. Following 30, 60 and 90 min incubations, statistical time-dependent differences were observed between the unlabeled and labeled cells with $16 \mu \mathrm{g} / \mathrm{ml}$ SPIONs $(\mathrm{P}<0.05$, for all values), but no significant differences in cell adhesion were observed between RCECs (normal) and 
RCECs (SPION) at these time points ( $\mathrm{P}>0.05)$ (Fig. 3A). Quantitative flow cytometric analysis revealed a time-dependent increase in Ki-67-positive cells in RCECs incubated with or without $16 \mu \mathrm{g} / \mathrm{ml}$ SPIONs, but no statistically significant differences were observed between the two cell lines after 24 or $36 \mathrm{~h}$ incubation $(\mathrm{P}>0.05)$. This demonstrates that $16 \mu \mathrm{g} / \mathrm{ml}$ SPION labeling did not alter the proliferation of RCECs (Fig. 3B and C). Cells labeled with $16 \mu \mathrm{g} / \mathrm{ml}$ SPIONs were immunostained for ZO-1 (a marker of cell tight junctions, Fig. 3D), nestin (a marker of immature cells, Fig. 3E) and for the cell proliferation marker Ki-67 (Fig. 3F).

Effects of SPIONs on potential differences and short circuit currents driven by $\mathrm{Na}^{+} / \mathrm{K}^{+}$-ATPase. The traces of potential difference and short circuit current driven by the $\mathrm{Na}^{+} / \mathrm{K}^{+}$-ATPase were similar shapes in the two cell lines after $24 \mathrm{~h}$ with $16 \mu \mathrm{g} / \mathrm{ml}$ SPION incubation. The potential differences and short circuit currents maintained corneal transparency and were reduced in the two cell lines by the presence of the $\mathrm{Na}^{+} / \mathrm{K}^{+}$-ATPase inhibitor ouabain (Fig. 4). This confirmed that the origin of the current is $\mathrm{Na}^{+} / \mathrm{K}^{+}$-ATPase.

\section{Discussion}

The development of new diagnostic and therapeutic technologies in nanomedicine includes nanotechnologies to improve the early detection and treatment of human diseases $(13,14)$. There is an urgent need to understand the mechanisms of interaction of nanomaterials, including nanoparticles, with living tissues and to define the consequences of these interactions (15-17). In this study, we used SPIONs to label RCECs and to observe several functions crucial for maintaining the dehydration and transparency of the cornea. TEM images (Fig. 2) show the spherical shape and confirm the size of the particles to be similar to $\xi$-size. The results of the MTT assay demonstrated that cells exposed to $16 \mu \mathrm{g} / \mathrm{ml}$ SPIONs at a mean size of $50 \mathrm{~nm}$ for $6 \mathrm{~h}$ resulted in no marked cytotoxicity. The morphology of the RCECs labeled by the SPIONs was similar to that of the unlabeled cells. Morphological observations and immunocytochemical staining confirmed that the cultured corneal endothelial cells were not contaminated by corneal fibroblasts or epithelial cells. Although the RCECs were directly cultured from the peeled corneal Descemet's membrane to which only endothelial cells are attached $(1,18)$, we were not able to demonstrate directly that the isolated cells led to RCECs due to the lack of specific markers $(2,20)$. However, the characteristic hexagonal morphology and several particular properties suggested that the cultures gave rise to cells with features of CECs (2,19-21).

CECs accumulate $\mathrm{Na}^{+} / \mathrm{K}^{+}$-ATPase at intercellular contacts along the lateral cell membranes in order to maintain a bicarbonate gradient across the cell and sustain a constant flow of water out of the stroma $(22,23)$. We used the Ussing chamber assay to detect cell pump function as evaluated by cell electrophysiological measurements. The presence of this protein in our RCEC populations indicated that SPION labeling with $16 \mu \mathrm{g} / \mathrm{ml}$ for $24 \mathrm{~h}$ did not alter pump function. Prior to the addition of ouabain, the potential difference and short circuit current was detected in the RCEC (normal) and RCEC (SPION) cell lines. Compared with the values of the RCEC (normal), RCEC (SPION) had a similar potential difference and short circuit current, indicating that a similar $\mathrm{Na}^{+} / \mathrm{K}^{+}$-ATPase activity exists in the two cell lines $(22,23)$.

We also demonstrated cell-cell adhesion with the homotypic adhesion assay (24), and the adhesion ability of RCECs was similar between the two cell lines during $90 \mathrm{~min}$ of cell culture. Quantitative flow cytometric analyses revealed the presence of Ki-67-positive cells in RCECs cultured with SPIONs for $36 \mathrm{~h}$. This suggests that SPION labeling did not interfere with the proliferation of RCECs.

Expression patterns of marker proteins are frequently utilized in CEC characterization. Intercellular tight junction-associated proteins of CEC cells, such as ZO-1, cell markers of proliferation proteins, such as $\mathrm{Ki}-67$, and intermediate filament proteins, such as nestin, are crucial in maintaining corneal dehydration and transparency $(19,21,24)$. Furthermore, certain adhesion junction-associated proteins mediate and strengthen close cell-cell and cell-matrix associations (25). In this study, the results of fluorescent immunocytochemistry revealed that RCEC (SPION) maintained the stable expression of ZO-1, Ki-67 and nestin, suggesting that SPIONs do not change these RCEC characteristics following labeling at a concentration of $16 \mu \mathrm{g} / \mathrm{ml}$ for $36 \mathrm{~h}$.

In conclusion, our study demonstrated that SPION labeling of RCECs at a specific concentration and time does not affect cell functions in any of the four assays that were used.

\section{Acknowledgements}

We would like to thank Dr Felix Bock and Dr Claus Cursiefen (Department of Ophthalmology, University Hospital of Cologne, Cologne, Germany) for technical advice and assistance with ophthalmic imaging and Dr Siwei Liu for preparing the donor tissues. Funding for this study came from the Natural Science Foundation of China (NSFC: 30973247/C170601, to Yanlong Bi) and Shanghai Excellent University Teacher Foundation (1500144019, to Yanlong Bi). Mingfeng Wu and Fei Du were partially supported by a stem cell traineeship from the Huadong Stem Cell Bank of China.

\section{References}

1. Okumura N, Ueno M, Koizumi N, et al: Enhancement on primate corneal endothelial cell survival in vitro by a ROCK inhibitor. Invest Ophthalmol Vis Sci 50: 3680-3687, 2009.

2. Joyce NC: Proliferative capacity of corneal endothelial cells. Exp Eye Res 95: 16-23, 2012

3. Yamazoe K, Yamaguchi T, Hotta K, et al: Outcomes of cataract surgery in eyes with a low corneal endothelial cell density. J Cataract Refract Surg 37: 2130-2136, 2011.

4. Pescosolido N, Komaiha C, Dapoto L, Lenarduzzi F and Nebbioso M: Corneal haze in course of Fuchs' endothelial dystrophy. Clin Ter 163: e169-e171, 2012.

5. Wang X, Wang W, Xu J and Wang Y: Analysis of causes of bullous keratopathy in East China: a 10-year retrospective study. Graefes Arch Clin Exp Ophthalmol 250: 307-308, 2012.

6. Quilendrino R, Yeh RY, Dapena I, et al: Large diameter Descemet membrane endothelial keratoplasty in buphthalmic eyes. Cornea: Nov 26, 2012 (Epub ahead of print).

7. Ang M, Mehta JS, Lim F, Bose S, Htoon HM and Tan D: Endothelial cell loss and graft survival after Descemet's stripping automated endothelial keratoplasty and penetrating keratoplasty. Ophthalmology 119: 2239-2244, 2012.

8. Jhanji V, Mehta JS, Sharma N, Sharma B and Vajpayee RB: Targeted corneal transplantation. Curr Opin Ophthalmol 23: 324-329, 2012. 
9. Peh GS, Beuerman RW, Colman A, Tan DT and Mehta JS, et al: Human corneal endothelial cell expansion for corneal endothelium transplantation: an overview. Transplantation 91: 811-819, 2011.

10. Patel SV, Bachman LA, Hann CR, Bahler CK and Fautsch MP. Human corneal endothelial cell transplantation in a human ex vivo model. Invest Ophthalmol Vis Sci 50: 2123-2131, 2009.

11. Mimura T, Yamagami S, Usui T, et al: Long-term outcome of iron-endocytosing cultured corneal endothelial cell transplantation with magnetic attraction. Exp Eye Res 80: 149-157, 2005.

12. Mimura T, Yamagami S, Yokoo S, et al: Cultured human corneal endothelial cell transplantation with a collagen sheet in a rabbit model. Invest Ophthalmol Vis Sci 45: 2992-2997, 2004.

13. Yue K, Guduru R, Hong J, Liang P, Nair $M$ and Khizroev S: Magneto-electric nano-particles for non-invasive brain stimulation. PLoS One 7: e44040, 2012.

14. Yang F, Jin C, Subedi S, et al: Emerging inorganic nanomaterials for pancreatic cancer diagnosis and treatment. Cancer Treat Rev 38: 566-579, 2012.

15. Raju HB, Hu Y, Vedula A, Dubovy SR and Goldberg JL: Evaluation of magnetic micro- and nanoparticle toxicity to ocular tissues. PLoS One 6: e17452, 2011.

16. Sun JH, Zhang YL, Qian SP, et al: Assessment of biological characteristics of mesenchymal stem cells labeled with superparamagnetic iron oxide particles in vitro. Mol Med Rep 5: 317-320, 2012

17. Balakumaran A, Pawelczyk E, Ren J, et al: Superparamagnetic iron oxide nanoparticles labeling of bone marrow stromal (mesenchymal) cells does not affect their 'stemness'. PLoS One 5: e11462, 2010.
18. Busin M, Scorcia V, Patel AK, Salvalaio G and Ponzin D: Donor tissue preparation for Descemet membrane endothelial keratoplasty. Br J Ophthalmol 95: 1172-1173, 2011.

19. Zhu YT, Hayashida Y, Kheirkhah A, He H, Chen SY and Tseng SC: Characterization and comparison of intercellular adherent junctions expressed by human corneal endothelial cells in vivo and in vitro. Invest Ophthalmol Vis Sci 49: 3879-3886, 2008.

20. Gao Y, Zhou Q, Qu M, Yang L, Wang Y and Shi W: In vitro culture of human fetal corneal endothelial cells. Graefes Arch Clin Exp Ophthalmol 249: 663-669, 2011.

21. Roh DS and Funderburgh JL: Rapid changes in connexin-43 in response to genotoxic stress stabilize cell-cell communication in corneal endothelium. Invest Ophthalmol Vis Sci 52: 5174-5182, 2011.

22. Hatou S, Yamada M, Akune Y, et al: Role of insulin in regulation of $\mathrm{Na}+-/ \mathrm{K}+-$ dependent ATPase activity and pump function in corneal endothelial cells. Invest Ophthalmol Vis Sci 51: 3935-3942, 2010

23. Hatou S, Yamada M, Mochizuki H, Shiraishi A, Joko T and Nishida T: The effects of dexamethasone on the Na,K-ATPase activity and pump function of corneal endothelial cells. Curr Eye Res 34: 347-354, 2009.

24. Chandrasekaran S, Geng Y, DeLouise LA and King MR: Effect of homotypic and heterotypic interaction in 3D on the E-selectin mediated adhesive properties of breast cancer cell lines. Biomaterials 33: 9037-9048, 2012.

25. Sugrue SP and Zieske JD: ZO1 in corneal epithelium: association to the zonula occludens and adherens junctions. Exp Eye Res 64: 11-20, 1997. 